\title{
AUTONOMIA, LIBERDADE E DEPENDÊNCIA DA MULHER: A POLÍTICA REDUCIONISTA DE CESARIANAS DESNECESSÁRIAS NO BRASIL E O BIODIREITO*
}

\author{
Paula Caroline Pepa Oliveira** \\ Rafael Lazzarotto Simioni ${ }^{* * *}$
}

\begin{abstract}
RESUMO
Esta pesquisa objetiva discutir a relação entre autonomia, liberdade e dependência da mulher a respeito do seu direito de escolha entre a via do parto normal ou da cesárea. Especialmente diante da especificidade da situação da mulher parturiente brasileira, que demonstra altíssimos índices de cesárea na rede de saúde complementar. Analisa-se a relação entre o conceito contemporâneo de pré-natal e as políticas públicas de saúde no Brasil, as diferentes atribuições dos enfermeiros, médicos e obstetrizes, bem como a política de diminuição das cesáreas desnecessárias institucionalizada pelas Resoluções ANS no 368/2015, 398/2016 e 409/2016. Através de uma metodologia analítica, a pesquisa apresenta, como resultado, uma reflexão crítica sobre a atual política da ANS, que ainda se encontra muito aquém da necessidade de garantia do direito de escolha mulher a respeito do seu tipo de parto, pois a distância entre a cultura brasileira da cesárea e o conceito global de parto humanizado ainda persiste muito presente tanto nos discursos das consultas médicas de pré-natal, quanto no imaginário social do século XX.
\end{abstract}

PALAVRAS-CHAVE: Cesárea. Parto normal. Saúde. Mulher. Biodireito.

\footnotetext{
*Artigo apresentado ao Mestrado da UNIVÁS como requisito parcial para conclusão de créditos da disciplina de Biodireito no ano de 2016.

*** Mestranda do Programa de Mestrado em Bioética da Univás, bolsista Capes, Pós Graduada em Enfermagem Obstétrica pela UNIFIL, Pós Graduada em Enfermagem em Neonatologia e Pediatria pelo UNIS.

*** Pós-Doutor em Teoria e Filosofia do Direito pela Universidade de Coimbra, Doutor em Direito pela Universidade do Vale do Rio dos Sinos, Mestre em Direito pela UCS, Professor do Programa de Mestrado em Bioética da Univás e do Programa de Mestrado em Direito da FDSM.
} 


\begin{abstract}
This research aims to discuss the relationship between autonomy, freedom and dependence of women about their right to choose between the path of normal delivery or cesarean section. Especially given the specificity of the woman Brazilian woman in labor situation, which shows very high cesarean rates in complementary health network. It analyzes the relationship between the contemporary concept of prenatal and health policies in Brazil, the different roles of nurses, doctors and midwives, as well as the reduction policy of institutionalized unnecessary cesareans by Resolutions ANS No 368/2015, 398/2016 and 409/2016. Through an analytical methodology, the research shows, as a result, a critical reflection on the current policy of the NSA, which is still far short of the need to guarantee the choice woman right about your type of delivery, because the distance between Brazilian culture of cesarean section and the overall concept of humanized labor still persists very much present in the speeches of prenatal medical consultations, and in the social imaginary of the twentieth century.
\end{abstract}

KEYWORDS: Cesarean section. Normal birth. Cheers. Woman. Biolaw.

\title{
1. INTRODUÇÃO
}

O número de partos cesáreas no Brasil é superior ao número de partos normais, especialmente na rede de saúde privada ou complementar. Contrariando normativas da Organização Mundial da Saúde, o número de cesáreas realizadas via plano de saúde privado no Brasil supera em quase três vezes limites recomendados em nível global. Em 2015 e 2016, a Agência Nacional de Saúde do Brasil, provocada por uma Ação Civil Pública movida pelo Ministério Público Federal de São Paulo, começou a instrumentalizar políticas de redução das cesáreas desnecessárias, por meio de três Resoluções: 368/2015, 398/2016 e 409/2016.

Essas resoluções procuraram instituir garantias para a transparência das informações a respeito da prática de cesáreas, de modo a oportunizar, à mulher, o direito de escolha entre a via do parto normal ou da cesárea. Trata-se de um importante passo em direção à autonomia e à liberdade da mulher. Mas que ainda está muito longe de provocar uma significativa transformação na cultura da cesárea que se construiu nas últimas décadas no Brasil. 
Nessa perspectiva, a questão central dessa pesquisa é discutir a relação entre autonomia, liberdade e dependência da mulher a respeito do seu direito de escolha entre a via do parto normal ou da cesárea. Especialmente diante da especificidade da situação da mulher parturiente brasileira, que demonstra altíssimos índices de cesárea na rede de saúde complementar, cuja clientela é formada, em sua maioria, por mulheres trabalhadoras, inseridas nos diversos mercados de trabalho, desde os chãos de fábrica até os cargos de gestão e liderança.

No que segue esta investigação objetiva a) analisar a relação entre o conceito contemporâneo de pré-natal e as políticas públicas de saúde no Brasil, b) descrever as diferentes atribuições e competências dos enfermeiros, médicos e obstetrizes, c) analisar o protagonismo do parto cesárea no Brasil e d) a atual revalorização do parto normal, bem como e) a política de diminuição das cesáreas desnecessárias institucionalizada pelas Resoluções ANS no 368/2015, 398/2016 e 409/2016. No final, será realizada uma reflexão sobre a relação entre autonomia, liberdade e o direito ao parto humanizado da mulher.

Para serem atingidos esses resultados, a pesquisa utiliza o método analítico e a técnica de pesquisa bibliográfica, no sentido de explicitar a relação entre os diversos procedimentos e conceitos envolvidos na prática da obstetrícia e as razões que levaram à definição normativa de regras e princípios do Biodireito sobre esse campo de estudo. No final, a pesquisa assume uma postura crítica no sentido de explicitar as deficiências e incoerências entre a cultura brasileira da cesárea e o conceito global do parto humanizado.

\section{O PRÉ-NATAL E AS POLÍticas PÚBLICAS DE SAÚdE NO BRASIL}

O pré-natal é uma avaliação que tem por objetivo reduzir o risco de adoecer e morrer, tanto da mãe quanto da criança. Entende-se por avaliação pré-concepcional a consulta que o casal realiza antes de uma gravidez, objetivando encontrar fatores de risco ou doenças que possam alterar a evolução normal de uma futura gestação. Constitui, assim, instrumento importante na melhoria dos índices de morbidade e mortalidade materno-infantil (BRASIL, Ministério da Saúde, 2012).

Segundo o Ministério da Saúde, as grandes maiorias das 
gestações no Brasil não são inicialmente planejadas, embora posteriormente desejadas. Pode-se dizer que essa falta de planejamento é ocasionada pelo déficit de orientação ou oportunidade para a aquisição de um método anticonceptivo, ocorrendo comumente com adolescentes e mulheres de baixa renda (BRASIL, Ministério da Saúde, 2012).

No Brasil há um número significativo nos indicadores de morbimortalidade materno e infantil, onde lamentavelmente essas mortes ainda ocorrem por causas evitáveis, especialmente quando diz respeito à atenção ao pré-natal, ao parto e ao recém-nascido. Embasado nesses indicadores, o Ministério da Saúde (2012) tem movimentado esforços para reduzir essas tristes taxas criando ações para qualificar as Redes de Atenção Materna Infantil do País e instituindo, por exemplo, a Rede Cegonha, como uma forma de complementação das políticas de saúde no campo da Saúde Complementar.

A Rede Cegonha vem com o intuito de melhorar a atenção à mulher no período gravídico. Trata-se de um conjunto de iniciativas que envolvem cuidados desde a gravidez até o nascimento, realizados por meio da qualificação dos profissionais envolvidos nesse cenário. A expectativa dessa política pública de saúde é promover uma assistência integral e humanizada ao pré-natal, parto, nascimento e puerpério (BRASIL, Ministério da Saúde, 2012).

Segundo o Ministério da Saúde (2012), o Brasil tem registrado redução na mortalidade materna desde 1900, porém a taxa ainda está aquém da desejada e sugerida pela Declaração do Desenvolvimento do Milênio da ONU. Essa redução se deve fundamentalmente á queda da mortalidade por causas obstétricas diretas, ou seja, complicações surgidas durante a gravidez, o parto ou puerpério (período de até 42 dias após o parto), decorrentes de omissões, tratamento incorreto ou uma cadeia de eventos condizentes com esses fatores. Já as mortes indiretas são ocasionadas por patologias preexistentes à gestação e que, de algum modo, foram agravadas pelo estado gravídico (BRANDEN, p. 73, 2000). As estratégias para diminuir os agravos à mulher e ao neonato iniciam com a assistência pré-natal adequada, passando pela qualificação da assistência ao parto.

Em 2001, a taxa de mortalidade materna no Brasil foi de 74,5 mortes por 100.000 nascidos vivos. Em países desenvolvidos, essa razão oscila de 6 a 20 óbitos por 100.000 nascidos vivos. Essas altas 
taxas brasileiras refletem também a qualidade do cuidado pré-natal oferecida pelo sistema de saúde. Sabe-se da íntima relação existente entre esses índices e o desenvolvimento de ações de saúde, por vezes singelas, dirigidas ao período pré-concepcional, gestacional e puerperal (BUCHABQUI, Jorge Alberto et al). Tais ações não dizem respeito somente aos usuários da saúde pública, mas também da saúde complementar, visto que muitas ações e práticas em saúde não são adequadamente realizadas no pré-natal da rede privada.

O diagnóstico da gravidez deve ser feito o mais precoce possível, para que haja um controle dos riscos e uma melhor avaliação do desenvolvimento fetal. Instalado o diagnóstico, inicia-se a assistência pré-natal, que consiste na supervisão médica e de enfermagem à gestante, desde a concepção até o início do trabalho de parto. Essa assistência é principalmente preventiva (CARVALHO, de Geraldo Mota).

Na primeira consulta deverá ser definido o plano de cuidados obstétricos continuados, sendo reavaliado em cada consulta. Segundo a Secretaria de Estado da Saúde (2004) é recomendável que sejam realizadas no mínimo seis consultas: uma no primeiro trimestre, duas no segundo e três no terceiro trimestre da gravidez. Porém o ideal é uma consulta a cada mês da gestação, diminuindo-se esse espaço de tempo quanto mais próximo do parto.

Atualmente, no Brasil é reconhecida a relevância de se ter um acompanhamento amplo no pré-natal, que envolva não só as questões biológicas, mas também aspectos emocionais e sociais relacionados com a gravidez. Esse conceito ampliado do atendimento ao pré-natal é uma diretriz do SUS voltada para operacionalizar a equidade e a integralidade no campo da saúde, permitindo superar uma atuação meramente curativa (BRASIL, Ministério da Saúde, 2006).

Por consideráveis motivos, a assistência pré-natal deve ser universalmente realizada e individualizada, diferindo no objetivo, no conteúdo, no número de consultas e no tipo de pessoal que presta assistência segundo o grau de risco que a gestante apresentar. Toda gestante deve vincular-se a uma unidade de saúde, seja pública ou privada, receber a carteira de gestante contendo informações relativas ao seu estado de saúde sempre atualizadas a cada consulta, as quais servirão de elo entre a assistência pré-natal e a assistência hospitalar (BUCHABQUI, Jorge Alberto et al). 


\section{ENFERMEIROS, MÉDICOS E OBSTETRIZES}

O termo obstetrícia vem da palavra latina obstetrix, que tem sua origem no verbo obstare (ficar ao lado), podendo ser definida como o ramo da medicina que estuda a gravidez e o parto (GUIMARÃES,2002,p.330). É uma ciência que estuda a reprodução humana, investigando a gestação, o parto e o pós-parto nas suas condições fisiológicas e patológicas. No Brasil existem três carreiras distintas da obstetrícia: o médico obstetra, o enfermeiro obstetra e a obstetriz, popularmente conhecida como a "parteira".

O médico não precisa de uma especialização ou outro tipo de pós-graduação para atuar na área da obstetrícia. Mas para tornar-se especialista em obstetrícia ele precisa participar de uma residência médica com duração de três anos, estando assim apto a prestar todo o cuidado ginecológico e obstétrico à mulher, incluindo o parto cesariano. Já o enfermeiro, conforme a Resolução COFEN 516/2016, para poder atuar no pré-natal, no parto e no puerpério, precisa realizar um curso de especialização ou comprovar experiência na área. Por outro lado, o profissional obstetriz realiza as mesmas funções do enfermeiro especialista em obstetrícia, com a diferença apenas na formação, já que sua graduação é focada na saúde da mulher (QUEIROZ, p. 1.2013).

Preceituado junto à legislação de número 7.498 de 25 de junho de 1986, que dispõe sobre a regulamentação do exercício profissional de enfermagem, em seu artigo 11, o qual declara que "o enfermeiro obstetra exerce todas as atividades de enfermagem, cabendo privativamente, como integrante da equipe de saúde, a assistência à parturiente, o acompanhamento da evolução do parto e execução do parto normal sem distócia, sendo permitida a realização da episiotomia e episiorrafia no qual esse profissional está amparado por lei para exercer suas atividades com eficiência e segurança" (COFEN, p. 3,4. 1986).

Considerando a importância do acompanhamento do trabalho de parto, visando à redução do índice de morbimortalidade materna e perinatal, bem como a necessidade de aprimoramento da assistência ao parto normal, o Ministério da Saúde (MS) inclui, em 1998, o procedimento "parto normal sem distócia" realizado pelo enfermeiro obstetra na sua tabela de informações hospitalares do sistema único 
de saúde (SIH/SUS), sendo um marco histórico na saúde do Brasil e na profissão da enfermagem (Ministério da saúde, p. 1-2. 1998).

Com isso, em 1999 o MS contemplou a criação dos Centros de Parto Normal (CPN), conhecido como "Casas de Parto", onde se realizam os partos normais de baixo risco com coordenação dos enfermeiros obstetras, bem como todos os cuidados necessários à puérpera e ao neonato. Em 2012 o MS reforça a participação do profissional enfermeiro na realização da consulta de pré-natal da gestação de baixo risco intercalada com a presença do médico (Caderno de atenção básica, p. 47. 2012).

Podemos dizer que tanto a obstetriz quanto o enfermeiro obstetra são responsáveis pelo acolhimento e orientação das mulheres durante a gestação, parto e o pós-parto. Esses profissionais acompanham todas as fases do ciclo gravídico-puerperal, devendo-se convocar o médico obstetra em caso de alto risco ou de complicações em qualquer fase do ciclo. Sendo assim, a meta primordial dos enfermeiros obstetras e obstetrizes é garantir a assistência integral e holística nessa fase tão especial e singular na vida da mulher, que é a gravidez (QUEIROZ, p. 2.2013).

Nessa perspectiva, a mulher e a criança não são objetos dos procedimentos de saúde, mas sim os personagens principais desse processo. Os profissionais da obstetrícia são colaboradores, coadjuvantes do parto, com o dever de reconhecer e agir se algo estiver ocorrendo de forma prejudicial à mãe ou ao bebê. O direito de escolha é unicamente da mulher. Os profissionais da obstetrícia devem incentivar a mãe a se apoderar do seu corpo com clareza a respeito das diversas situações e prováveis cenários da sua saúde em seu contexto de vida, colocando em prática a sua autonomia livre e esclarecida.

\section{O PROTAGONISMO DO PARTO CESÁREA}

O parto é um momento singular na vida de todos os envolvidos, repleto de expectativas, de emoções ambivalentes como o medo e a esperança juntos, além da própria rede de significações antropológicas que ele simboliza, como a ideia da continuidade da vida, do dar à luz e da instituição da herança.

Do ponto de vista da saúde, pode-se definir o parto como "o 
momento do ciclo gravídico-puerperal em que ocorrem as mais intensas mudanças orgânicas, corporais e as emoções mais fortes, em um curto período de tempo, além de ter um significado cultural representando o início de uma vida, a continuação da espécie" (FREITAS et.al. p. 202. 2006). Envolto por todos esses aspectos, o parto se transforma em um momento complexo, bem maior que um simples procedimento de saúde, visto que é um processo irreversível, ou seja, uma situação que precisa ser enfrentada de qualquer maneira.

Sentimentos paradoxais de medo e, ao mesmo tempo, de esperança, são as emoções mais fortes e frequentes que giram em torno desse processo. Mesmo que a mulher já tenha tido outras experiências, eles não deixam de existir. Medo de acontecer algo maléfico com ela e principalmente com seu bebê e, ao mesmo tempo, esperança de saúde e de vida plena.

O nascer geralmente envolve toda a família e, mesmo em gestações não planejadas ou indesejadas, o nascimento é um momento de muita emoção. E é exatamente nesse contexto predominantemente emocional que a gestante e sua família procuram o serviço de saúde, a fim de buscar uma assistência qualificada e garantidora da integridade física e emocional sua e de seu filho que está a chegar. Sendo assim, o profissional médico, enfermeiro ou obstetriz, que irá realizar esse acolhimento, deverá estar bem preparado para esse momento singular e tão especial na vida dessa família (BRANDEN, p. 220, 2000).

Nessa fase bastante emotiva da mãe e sua família, não é fácil ter clareza a respeito da escolha entre os procedimentos de parto normal ou de cesariana. Muitas vezes submetida à opinião hegemônica do profissional da saúde ou, como às vezes acontece no Brasil, mães em situação de vulnerabilidade social, não possui a liberdade e autonomia para escolher realizar o seu parto de modo normal ou por cesariana. Não se trata apenas de uma questão de imposição do hospital, do plano de saúde ou do profissional de saúde. O problema do parto no Brasil é que a escolha entre o normal ou a cesariana parece não existir como uma realidade institucional. A prática da cesariana é esmagadoramente predominante tanto entre mulheres que fazem parte das populações mais vulneráveis, quanto entre as mulheres que possuem maiores graus de escolaridade ou que fazem parte de classes sociais mais altas. 
"A cesariana é definida como o nascimento do feto mediante incisão nas paredes abdominal (laparotomia) e uterina (histerotomia)" (FREITAS, p. 282. 2006). Tal forma de extração fetal tem feito parte da cultura ocidental e oriental desde tempos remotos, onde era realizada após a morte materna. Na Roma Antiga sabe-se da existência desse procedimento e o nome "cesariana" faz alusão ao imperador romano Júlio Cesar. Naquela época, era proibido enterrar uma mulher grávida. Ocasião em que a cesariana era obrigatória para retirar o feto do corpo da mãe morta. Apenas no século XIX, na Europa, há registros de que a cesariana começou a se realizada em mulheres vivas, porém com taxas de mortalidade materna em torno dos 67\% (FREITAS, p. 283. 2006).

Com o passar do tempo, as técnicas cirúrgicas foram sendo aprimoradas, especialmente as técnicas de assepsia. Foram descobertos os antibióticos, a anestesia, a assepsia e assim a morbidez e mortalidade materna foram diminuindo. Hoje não restam dúvidas sobre o grande valor da cesariana para salvar vidas tanto maternas quanto fetais, bem como prevenir seqüelas neonatais (QUEIROZ, p. 2. 2013). Porém, o emprego desmedido da cesariana provocou o descontrole no uso dessa técnica no Brasil. Indicada indiscriminadamente, a cesariana pode elevar o risco de morbimortalidade materno e fetal. Ao invés dos benefícios que ela apresentou no salvamento de vidas e na prevenção das sequelas neonatais, o uso indiscriminado da cesariana, hoje, produz riscos à saúde das mães e bebês.

Como observa Moraes (2001, p. 88) "Existem hipóteses confirmadas de que os obstetras tendem a deliberar o parto cirúrgico, por ser uma estratégia que possibilite administrar melhor o tempo, resultando no atendimento do interesse econômico pessoal". Com efeito, os índices da realização do parto cesariana são bem distintos segundo diversos grupos. Mas ao contrário do que se poderia supor, no Brasil não são as mulheres de classes mais baixas que se encontram nos maiores índices de práticas de cesariana e sim as mulheres das classes mais altas. Segundo Freitas (p. 283, 2006), a cesariana "é mais realizada em populações de maior poder aquisitivo, que tem planos de saúde privados e com mais acesso ao atendimento por médico especialista em obstetrícia".

No ano de 2014, segundo dados do sistema de informações 
sobre nascidos vivos (SINASC), tivemos no Brasil um total de 2.979.259 nascimentos, sendo 1.697 .954 de partos cesáreas, 1.277.175 partos normais e 4.130 foram ignorados. Ao fazer uma retrospectiva, pode-se visualizar que até o ano de 2008, os números de partos normais superavam os partos cesarianas, sendo que essa inversão ocorreu em 2009 e se mantêm até os dias atuais.

Chama a atenção o fato dessa crescente fase "cesariana" dos partos não ser uma característica apenas do Brasil, mas sim um cenário mundial. Exatamente diante desse cenário, em 2014 a Organização Mundial da Saúde (OMS) realizou um estudo sobre a associação das taxas de cesáreas e desfechos maternos, perinatais e infantis. Com base nos resultados alcançados, a OMS publicou relatórios informando que as "taxas populacionais de cesáreas de até 10-15\% estão associadas a uma diminuição na mortalidade materna e neonatal, porém não há associação entre aumento nas taxas de cesáreas acima desses valores e redução na mortalidade (OMS, p. 3. 2014).

Assim, enquanto a OMS recomenda que apenas 10 a $15 \%$ dos partos sejam cesariana, no Brasil a prática da cesariana atinge índices de $57 \%$ dos partos, como aconteceu em 2014. Observando a distância entre os valores brasileiros e o recomendado pela OMS, pode-se perceber o impacto das mudanças nas políticas de saúde no campo da obstetrícia. Considerando os dados de 2014, mais de 1 milhão das cesarianas realizadas deveriam ter sido partos normais. Por isso que, objetivando reduzir esse índice de cesarianas, o Ministério da Saúde (MS) passou a priorizar estímulos e iniciativas no sentido de valorizar o parto normal tanto na saúde pública, quanto na complementar.

\section{A REVALORIZAÇÃO DO PARTO NORMAL}

Embora ainda associado a uma ideologia naturista, zen ou até mesmo hippie, o parto natural encontra hoje uma revalorizada importância.

O parto normal é um processo fisiológico, onde ocorre à saída do bebê pelo canal vaginal sem qualquer intervenção cirúrgica, sendo assistido por um profissional qualificado, e que, usualmente é realizado no hospital (Revista enfermagem, p. 22. 2009). Nem sempre o parto normal é realmente "normal". Talvez fosse melhor designar 
esse tipo de processo como parto natural ao invés de normal. Já que a normalidade do parto natural dependerá da harmonia entre pelo menos três condições fisiológicas: o feto, o canal de parto e a força das contrações. Nesse sentido, "o trabalho de parto é caracterizado por uma complexa interação de fatores contribuintes para o nascimento do concepto. Para que ocorra o parto adequadamente, três fatores devem ser considerados: o feto, o canal de parto e a força que move o feto (contrações)" (OLIVEIRA in Carvalho, p. 153. 2007). Da união e harmonia desses fatores é que ocorre a normalidade do parto vaginal, que é um processo contínuo e gradual, podendo levar de 1 até 24 horas do seu inicio até o nascimento do bebê.

Por ser um processo lento e doloroso, a parturiente deve ser acolhida psíquica e fisicamente pela equipe e pelo seu acompanhante. Lento, doloroso, porém um processo fisiológico, no qual a parturiente deve ser encorajada a vencer e ter seu maior presente em seus braços com segurança.

Carvalho (p. 111. 2007), relata que a mulher foi e continua sendo condicionada pela família, pelos meios de comunicação e pela comunidade que a cerca a associar o parto à dor e ao perigo e a encarar o parto como um acontecimento antinatural, cercado de sofrimento e dores intensas. Não podemos negar que a dor no trabalho de parto é real e tão pouco subestimar a agonia que algumas mulheres sentem nessa hora. Entretanto, mesmo assim não há razão para associar o parto vaginal ao sofrimento. Primeiro porque o parto cesariana também não está livre de sensações dolorosas. E segundo porque a dor é parte natural do processo de parturição, mas que pode ser controlada e administrada com técnicas naturais e se necessário com analgésicos. O parto vaginal pode e deve ser uma experiência positiva e alegre.

O parto vaginal é um processo que se inicia na infância, porém a mulher é condicionada negativamente desde criança em relação ao parto, recebendo informações do seu meio que ressaltam apenas o lado dos sofrimentos, da dor e do cansaço. A mídia de massa não apresenta o outro lado do parto normal, que são as vantagens na recuperação, na saúde do bebê, as técnicas naturais e não invasivas de lidar com a dor e a alegria possível dessa experiência singular na vida da mulher. A parturiente tem um desafio, que é desenvolver sua confiança, contar com sua sabedoria interior e permitir que a natureza faça seu trabalho (CARVALHO, p. 112-113. 2007). 
Oliveira (p. 668, 2002) compara o risco de morte materna segundo o tipo de parto e relata que vários estudos nacionais e internacionais revelam maior morbimortalidade materna entre mulheres submetidas à cesárea, devido a infecções puerperais, acidentes e complicações anestésicas. Confirmando esse relato, estudos da OMS demonstram que o parto cesárea esta associado à maior probabilidade de internação para a mãe e para o recémnascido, ressaltando que o procedimento não deve ser evitado, mas sim realizado somente quando há risco para a mãe e/ou para o bebê.

Uma das preocupações do poder público é com o alto índice de mortalidade materna e neonatal, que por muito tempo fez parte do cenário da saúde da mulher no Brasil. E na tentativa de rever esse cenário, o Ministério da Saúde lançou, em 2004, a Política Nacional de Atenção Integral à Saúde da Mulher, implementando assistência em todas as fases da vida da mulher, além de direcionar as mesmas para que tenham mais apropriação, autonomia e um controle maior sobre a sua saúde, o seu corpo e a sua vida. Para que haja a participação da mulher no seu processo de cuidar, é reconhecido o alto valor às práticas educativas, entendidas como estratégias para a capacidade crítica e de autonomia das mulheres (ALCÂNTARA, p. 61. 2013).

Alimentados por tantos conceitos referentes aos prós e contras das vias de parto, pode-se dizer que tanto o parto normal quanto o parto cesárea têm as duas faces da moeda, podendo ser tanto benéficos quanto maléficos, dependendo do tipo de avaliação e indicação. Vale ressaltar a participação da mulher na escolha da sua via de parto, visto que ela é a principal protagonista desse cenário, cabendo ao profissional que irá assisti-la fomentar o conhecimento acerca das duas vias, dando autonomia para que a gestante, juntamente com sua família, faça a escolha que assim achar melhor para si, embasada em conhecimento e não em imposição.

\section{A POLÍTICA DE DIMINUIÇÃO DAS CESÁRIAS DESNECESSÁRIAS E AS RESOLUÇÕES ANS No 368/2015, 398/2016 E 409/2016}

Com o passar dos anos a mulher foi conquistando seu espaço na sociedade e, hoje ela se encontra em um patamar de igualdade com os homens. Esta correria diária da mulher moderna gerou 
ganhos, porém também perdas. Hoje já quase não se vê a mãe cuidando do seu filho, sendo esse lugar ocupado pelas avós, babás ou instituições escolares. Nesse capitalismo industrial ou pós-industrial que avassala a vida contemporânea, o tempo é precioso e as atividades são calculadas minuciosamente.

Nessa turbulenta vida moderna, a comodidade de se poder agendar a data e horário do parto são bem vindos e, por isso, Moraes (p. 88. 2001) conclui que o "parto cesariano é um modismo onde a mulher de ativa e participante torna-se passiva, e na grande maioria das vezes o parto natural dá lugar ao parto cirúrgico". Confirmando a vida atarefada da mulher devido ao seu espaço no mercado de trabalho, esse estudo aponta um maior número de parto cesárea realizado em mulheres com maior poder aquisitivo, escolaridade acima de 12 anos e que possui plano de saúde.

Mas a mulher se auto-engana ao achar que a escolha pela data e hora do seu parto é uma conquista. Nessa aparente liberdade pode haver uma comodidade e conveniência camufladas e não uma escolha informada e consciente. A mulher quer ser tão livre e acaba perdendo sua autonomia no momento mais importante da sua vida: o nascimento do seu filho. Obtém tantos conhecimentos e controle de vastas situações, porém nesse momento que é só seu, do seu corpo, não têm informações necessárias sobre os riscos e benefícios das vias de parto e, por vezes, acaba sendo influenciada pelo medo de sentir dor ou pelo seu pré-natalista.

Há estudo que relata a passividade da gestante frente ao médico no que procede a decisão pela via de parto. A vulnerabilidade da mulher desencadeada pelo processo parturitivo, somada à detenção do conhecimento pelo médico que realiza o pré-natal, resulta que a gestante passa a valorizar mais a opinião do médico do que a sua vontade livre e consciente (FIGUEIREDO et. al. p. 303. 2010). Oliveira (p. 668, 2002) também reconhece que a institucionalização do parto e os avanços tecnológicos proporcionaram um melhor controle dos riscos materno-fetais, porém observa que houve a incorporação de um grande número de intervenções desnecessárias.

A cesárea dá ao médico o máximo de poder, controle e condução no parto e exige, por sua vez, o mínimo de trabalho do útero da mulher. Por isso que, entre alguns médicos obstetras, instituiu-se a 
cultura da cesárea indiscriminada, a cesariana em qualquer hipótese, inclusive nas que ela seria desnecessária. Como consequiência, parte deles não se encontra motivada, tampouco capacitada para o acompanhamento do parto normal (PIMENTA, p. 142.2013).

No Brasil, as taxas de partos cesáreas são muito além do que é preconizado pela OMS e esses valores são maiores ainda quando se trata da rede privada, chegando até $84 \%$ dos partos realizados. Esse protagonismo da cesariana não pode mais se sustentar apenas com base na comodidade, já que permitem a compatibilização de agendas entre mães e médicos e a relativa praticidade do procedimento cirúrgico, que não dura mais de duas horas. A sociedade deve entender que a saúde materna e fetal é mais importante do que a agenda de compromissos profissionais dos médicos e das mães.

Como estratégia para diminuir a realização de partos cesárea desnecessários, o MS, juntamente com a Agência Nacional de Saúde, propôs em 2015 aos planos de saúde a Resolução no 368 que "dispõe sobre o direito de acesso à informação das beneficiárias aos percentuais de cirurgias cesáreas e de partos normais, por operadora, por estabelecimento de saúde e por médico e sobre a utilização do partograma, do cartão da gestante e da carta de informação à gestante no âmbito da saúde suplementar" (ANS, p. 1.2015).

Essa Resolução foi posteriormente complementada pela Resolução ANS 398/2016 e pela Resolução ANS 409, de 22/07/2016, ao instituir a obrigatoriedade de fornecer, a todas as parturientes, um documento chamado "Nota de Orientação à Gestante", com informações acerca da importância da escolha do parto normal e da necessidade do uso da cesárea apenas em situações de risco, já que, conforme literatura citada no documento, "Cesarianas triplicam o risco de morte materna, bem como que cerca de $25 \%$ dos óbitos neonatais e $16 \%$ dos óbitos infantis no Brasil estão relacionados à prematuridade" (Resolução ANS n. 409/2016).

O conjunto dessas Resoluções, contudo, apresenta certa ambiguidade política, pois ao mesmo tempo em que parecem fazer parte de uma política do Ministério da Saúde no sentido de garantir a transparência, a publicidade e a informação no que diz respeito a taxas de cesáreas desnecessárias praticadas por hospitais, planos e profissionais da saúde, trata-se de uma Resolução fruto de uma determinação judicial e não de uma iniciativa política do próprio 
Ministério da Saúde ou da Agência Nacional de Saúde. Essa resolução só existe porque, cumprindo uma ordem judicial expedida nos autos da Ação Civil Pública nº 0017488-30.2010.4.03.6100, do TRF da Terceira Região, a ANS não teve alternativa senão editá-la e publicá-la naqueles termos.

A Resolução 368/15, com as atualizações pelas Resoluções 398/16 e 409/16, apresenta uma importante inovação no âmbito demonstrativo quantitativo dos partos normais e cesáreas e na obrigatoriedade do partograma, que "é um gráfico utilizado para registrar a evolução do trabalho de parto e as condições da mãe e do feto" (CARVALHO, p.163.2007). Mas se apresenta muito aquém da necessidade de uma mudança de cultura nos meios de comunicação de massa, na família, no trabalho e na vida comunitária da mulher.

\section{AUTONOMIA, LIBERDADE E DIREITO AO PARTO HUMANIZADO}

Na Ação Civil Pública nº 0017488-30.2010.4.03.6100 (TRF3), movida pelo Ministério Público Federal de São Paulo contra a Agência Nacional de Saúde, o objetivo do Ministério Público foi obrigar a ANS a implantar políticas de redução das cesáreas, por meio de seis estratégias: a) o acesso à informação dos percentuais de cesárea praticados por hospitais, planos de saúde e médicos; b) a definição de um modelo de partograma para tornar obrigatório o seu uso pelo profissional obstétrico, como condição de recebimento da remuneração pela operadora; c) obrigatoriedade do uso do cartão da gestante; d) obrigatoriedade da contratação e credenciamento de enfermeiros obstétricos para atuar tanto no trabalho de parto, quanto no parto; e) criação de indicadores e notas para qualificação de operadoras de planos de saúde e hospitais no contexto das políticas de humanização dos partos e redução de cesáreas; e f) determinar maior remuneração dos honorários médicos para a realização de parto normal do que para cesárea.

A questão é interessante porque não se trata de determinar um teto ou índices máximos de cesárea por plano ou médico por ano, tampouco obrigar o cumprimento de metas de realização de partos normais. O objetivo é reduzir o número de cesáreas, mas não pela via da determinação de limites e sim pela via da autonomia e da 
liberdade da mulher parturiente. A questão é informar a mulher com clareza e honestidade, de modo a oportunizar a ela o direito de escolha entre a cesárea e o parto normal.

O objetivo agora não é convencer a mulher a fazer parto normal apenas para atingir os índices recomendados pela Organização Mundial de Saúde, mas sim oportunizar e respeitar sua liberdade de escolha. É garantir a parturiente a possibilidade dela escolher, com liberdade, autonomia e esclarecimento, qual será o método mais adequado à sua necessidade, ao seu modo de vida, às suas convicções.

Sociedades historicamente desiguais como a brasileira parecem estar acostumadas às soluções técnicas, às "soluções finais" da ideologia das guerras e dos campos de concentração do século XX. Mulheres integrantes de grupos sociais vulneráveis, seja pela baixa renda, sejam pela baixa escolaridade, muitas vezes acabam se submetendo às decisões técnicas de quem domina, com exclusividade e competência, o uso dessas tecnologias médicas. Na realidade brasileira, as mulheres que fazem parte desses grupos não são apenas aquelas que utilizam a rede pública de saúde, mas também aquelas mulheres de baixa escolaridade, que trabalham em indústrias com o plano de saúde particular como benefício ou que exercem cargos de liderança tão exigentes que elas não possuem alternativa senão ceder à praticidade e à conveniência da técnica.

Em qualquer uma dessas hipóteses há um desrespeito à autonomia e a liberdade da mulher. Na primeira situação, mulheres trabalhadoras que possuem tempo, possuem disposição, mas não possuem nenhuma oportunidade de discernimento sobre o estado atual das técnicas de parto e sobre a possibilidade de escolha entre os diferentes métodos. Na segunda situação, mulheres igualmente trabalhadoras, mas que não possuem tempo, nem disposição, para escolher métodos mais humanizados de parto, já que, inseridas em um mercado de trabalho hipercompetitivo, seus cargos de liderança exigem, dentre outras decisões, a renúncia à sua própria individualidade em prol de uma entrega total ao trabalho, ao serviço dos mercados e ao mundo técnico das sociedades industriais ou pósindustriais que vivemos.

A grande maioria das mulheres que fazem parte da clientela dos planos de saúde privados são mulheres trabalhadoras. Desse universo 
do mercado de trabalho, pouquíssimas deixam de trabalhar antes do parto, durante o período da gestação. E pouquíssimas deixam de trabalhar após o parto, durante o período da amamentação, que naturalmente continua após a licença maternidade de 4 a 6 meses dependendo da categoria profissional. Se isso realmente se verifica na realidade brasileira, então é fácil entender porque o número de partos cesáreas são tão alto na rede de saúde privada ou complementar.

As mulheres trabalhadoras encontram-se submetidas a uma exigência de competitividade e dedicação aos seus trabalhos que o tempo de dedicação exigido para a realização de um parto normal se torna um grande inconveniente. Somado a isso, o inconveniente do profissional da saúde, que encontra na cesárea a rapidez e o controle muito mais eficaz e otimizado do procedimento do parto, transformaram o parto normal em símbolo de uma prática aparentemente medieval. Uma prática ligada à ideia de povos e culturas antigas, de um tempo no qual não existiam as maravilhas e avanços tecnológicos de hoje.

Mais do que o cumprimento de metas definidas por políticas globais e locais de saúde, hoje é importante entender com clareza que a questão do parto cesárea ou normal é um direito da mulher. Um direito de escolha. E para isso se torna necessária à adoção de medidas que visem garantir a transparência de informações, o esclarecimento a respeito dos riscos, perigos e benefícios de ambas as possibilidades e, principalmente, a honestidade e a integridade de todos os profissionais da obstetrícia a respeito da situação da parturiente e do seu futuro bebê. Isso significa que apenas dois motivos podem justificar, com honestidade e integridade, a realização de um parto cesárea: a) a especificidade do quadro de saúde da parturiente ou do feto; e b) a vontade livre, esclarecida e consciente da parturiente.

E se em algum momento houver uma colisão entre, de um lado, a necessidade de se fazer uma cesárea em razão do quadro de saúde da mulher ou do feto e, do outro lado, a vontade da mulher de não realizar cesárea por motivos religiosos, culturais, tradições familiares ou outras justificativas pessoais, os profissionais da obstetrícia devem priorizar sempre a vida digna. Pois a vida e a dignidade são, atualmente, princípios jurídicos mais importantes do que a liberdade de crença religiosa ou de opinião. Por isso, 
exatamente em razão de ainda existirem situações médicas que exigirão a realização de cesárea contra a vontade da mulher, torna-se muito importante evitar a prática de cesáreas desnecessárias e priorizar a vontade da mulher, livre e esclarecida, de escolher entre o tipo de parto que ela quer para si.

Fica em questão o desafio da emancipação da mulher diante das exigências do mercado de trabalho, da ideologia dos meios de comunicação de massa e da família ou da comunidade. Autonomia esclarecida e liberdade de escolha constituem os primeiros pilares ou as primeiras virtudes para a garantia do direito da mulher. Mas a emancipação da mulher a respeito dos grilhões do mundo capitalista ainda constitui um grande desafio para o pensamento político do século XXI.

\section{CONSIDERAÇÕES FINAIS}

Historicamente, no Brasil, a decisão sobre a saúde de um paciente foi por muito tempo um ato de poder ligado ao profissional da saúde. Seja ele médico, enfermeiro ou obstetriz, o poder de escolha sempre foi um poder exclusivo do profissional da saúde. $\mathrm{O}$ resultado dessa cultura da apropriação epistêmica da saúde pela ciência médica, somada ao ingresso das mulheres em um mercado de trabalho assalariado hipercompetitivo, foi a proliferação de uma cultura da cesárea como o modo mais rápido, seguro e moderno de realização do parto. Enquanto que, ao mesmo tempo, ao parto normal ficou endereçado ao lugar do sofrimento, da dor, da insegurança, da imprevisibilidade, da perda de tempo e ancestralidade.

A cultura da cesárea no Brasil se edificou sob o discurso da ciência e da tecnologia, enquanto que o parto normal ficou atribuído a uma velha cultura dos nossos antepassados, que se reproduz hoje mais como um sofrimento de parto do que como uma alegria da vida. Um sofrimento que, naquela época, tinha que ser enfrentado corajosamente pela mulher em razão da ausência de outras alternativas. E não como um processo natural e alegre, que simboliza o "dar à luz" à vida.

A cesárea, como todas as demais tecnologias da sociedade moderna, são criadas para auxiliar a vida. Mas logo que criadas, apresentam-se com sua hegemonia e utilidade a ponto de substituir por 
completo aquilo que visavam apenas auxiliar ou complementar. Como uma prótese que, sem se perceber, já se tornou mais importante e falaciosamente mais necessária do que o membro natural.

Humanizar o parto, nessa perspectiva crítica, pode ressignificar o sentido da cesárea, de uma tecnologia modernista baseada na eficiência instrumental e estratégica, para uma prática artificial e colonizadora de uma das mais importantes e singulares experiências de vida que uma mulher pode vivenciar. Para não desperdiçar a singularidade dessa experiência do parto é que não se pode obrigar, alienar ou iludir a mulher a respeito das possibilidades naturais e artificiais de realização do parto. É necessário honestidade, integridade e transparência para oportunizar não o cumprimento de metas hospitalares de parto normal, mas sim o direito de escolha da mulher.

Isso porque, a única hipótese sob a qual não se pode admitir esse direito de escolha da mulher é quando, por razões médicas comprovadas, o quadro de saúde da parturiente ou do feto exige a cesárea como condição de possibilidade da saúde, da vida ou da dignidade. Convicções religiosas, culturais ou opiniões políticas não tem relevância aqui. Isso significa, em outras palavras, que a decisão sobre o tipo de parto não é uma decisão que cabe exclusivamente ao profissional da saúde e sim uma decisão que compete à mulher, salvo se existir um quadro de saúde que justifique, comprovadamente, a realização da cesárea mesmo contra a vontade da mulher.

A regra é a de que a mulher decide se quer ter parto normal ou cesárea. Ela possui a legitimidade para tomar essa decisão porque essa escolha é direito seu. Tem fundamento nos princípios da autonomia e da liberdade. A única hipótese em que o profissional da saúde pode contrariar esse direito de escolha da mulher pela via do parto é quando, comprovadamente, a parturiente ou o feto apresenta um histórico ou quadro de saúde que exige a realização da cesárea. Isso porque, nessa hipótese, a adjudicação do direito de escolha pelo profissional da saúde viola os princípios da autonomia e da liberdade da mulher, mas encontra fundamento em outros princípios que, atualmente, são mais importantes nesses casos: os princípios da saúde, da vida e da dignidade.

Trata-se da mesma razão pela qual um médico deve realizar procedimento cirúrgico mesmo quando esse procedimento contrarie as convicções religiosas da paciente. Ou pela qual um cidadão livre 
não pode, com base na sua liberdade, vender a si mesmo para a escravidão. Ou justificar o não uso de capacete em motocicletas ou cinto de segurança em veículos ou ainda justificar o consumo de drogas e substancias maléficas à saúde com base em uma suposta liberdade. A vida, a saúde e especialmente a dignidade estão em primeiro lugar na ordem jurídica contemporânea. De modo que, apenas por razões de saúde, de vida e de dignidade é que o profissional da saúde pode usurpar o direito de escolha do parto da mãe para decidir, por si só, pela via da cesárea.

Não se pode deixar de reconhecer o valor dessa recente normativa da Agência Nacional de Saúde na melhoria do atendimento à gestante. Porém, tal resolução dificilmente mudará o cenário "cesariano" que a saúde complementar se encontra, visto que, na realidade brasileira, a via de parto é decidida anteriormente ao início do trabalho de parto, ou seja, no consultório médico. Portanto, há muito que se fazer ainda para que esses alarmantes números sejam diminuídos, não bastando somente a gestante ter informação de qual médico conveniado ao seu plano de saúde realiza mais ou menos intervenções cirúrgicas no parto.

Vale ressaltar que o parto via cirúrgico é correto quando bem indicado, visto que o contrário é temeroso, pois se trata de uma cirurgia abdominal de médio porte, apresentando riscos como infecção, trombose, hemorragia, prematuridade, problemas respiratórios para o recém-nascido, entre outros, devendo assim ser colocado na balança os riscos e benefícios das duas vias de parto: normal e cesariana. Além da importância de se ter presente que essa decisão é uma questão conjunta e informada, entre médico, enfermeiro, profissionais envolvidos no processo de parturição e, principalmente, a gestante.

Mais do que autonomia e liberdade da mulher, no Brasil tornase necessário pensar também na emancipação social da mulher. Na emancipação da mulher no sentido da ruptura com os grilhões que prendem sua possibilidade de escolha a um único e hegemônico cenário, constituído tanto pelas exigências pouco humanistas dos diversos mercados de trabalho, quanto pelas ideologias reproduzidas nos meios de comunicação de massa, na família e na comunidade. 


\section{REFERÊNCIAS}

AGÊNCIA NACIONAL DE SAÚDE - ANS. Resolução normativa 368/2105. Disponível em:

<http://www.ans.gov.br/index2.php?option=com_legislacao\&view=legislac ao\&task=TextoLei\&format=raw\&id=2892> Acessado em: 08 junho 2016

ALCÂNTARA, Francisco Antônio Lopes de; SILVA, Márcia Mara Cavalcante da.; ABREU, Milena de Melo; ARAGÃO, Antonia Eliana de Araújo. REVISTA FORMAR INTERDISCIPLINAR. Vou parir! Que tipo de parto? A decisão é da parturiente ou do médico? Sobral - Ceará: 2013 jul-dez. v. 1, n. 3, p. 60-68.

BRANDEN, Pennie Sessler. Enfermagem materno infantil. Enfermagem prática.2.ed.Rio de Janeiro: Reichmann e Affonso Editores, 2000. p. 73,220.

BRASIL. Ministério da Saúde. Manual técnico. Pré-natal e puerpério. Atenção qualificada e humanizada, nº5. Brasília-DF, 2006. p. 9

BRASIL. Ministério da Saúde. Cadernos de atenção básica. Atenção ao pré-natal de baixo risco, $\mathrm{n}^{\circ} 32$. Brasília-DF, 2012.

BUCHABQUI, Jorge Alberto et al. Assistência pré-natal. In: FREITAS, Fernando et al. Rotinas em obstetrícia. 5. ed. São Paulo: Artmed, 2006. p. 25-28.

CARVALHO, Geraldo Mota de. Enfermagem em obstetrícia. 3.ed. rev. e ampl. São Paulo: E.P.U, 2007. p. 5.

CONSELHO FEDERAL DE ENFERMAGEM. Profissional. Legislação.

LEI N $\mathbf{N}^{\circ}$ 7.498/86, DE 25 DE JUNHO DE 1986. p. 1-6. Dispõe sobre a regulamentação do exercício da Enfermagem e dá outras providências. Disponível em: http://site.portalcofen.gov.br/node/4161 Acesso em: 06 junho 2016.

FIGUEIREDO, Nathália Stela Visoná de. et. al. HU Revista. Fatores culturais determinantes da escolha da via de parto por gestantes. Juiz de Fora: MG, v. 36, n. 4, p. 296-306, out./dez.2010.

FREITAS, Fernando; COSTA, S.H.M; RAMOS, J.G.L; JOSÉ, A.M. Rotinas em obstetrícia. 5 ed. Porto Alegre-RS: ARTMED Editora S.A 2006. Cap. 16-19-23.

MINISTÉRIO DA SAÚDE. Departamento Nacional de Auditoria do SUS. Coordenação de Sistemas de Informação. Sistema Único de Saúde Legislação Federal. PORTARIA No $\mathbf{N}^{\circ}$.815/GM DE 29 DE MAIO DE 1998. Trata da inclusão na tabela do Sistema de Informações Hospitalares do Sistema Único de Saúde (SIH/SUS) de procedimentos e valores para assistência ao parto sem distócia por enfermeiro. Disponível em: 
<http://sna.saude.gov.br/legisla/legisla/obst/GM_P2.815_98obst.doc> Acesso em: 05 junho 2016.

MINISTÉRIO DA SAÚDE. DATASUS tecnologia da informação a serviço do SUS. MS/SVS/DASIS - Sistema de Informações sobre Nascidos Vivos SINASC. Disponível em:

<http://tabnet.datasus.gov.br/cgi/tabcgi.exe?sinasc/cnv/nvuf.def >

Acessado em: 06 junho 2016

MORAES, Leila Memória Paiva; CARDOSO, Maria Vera Lúcia Moreira Leitão; ORIÁ, Mônica Oliveira Batista; SILVEIRA, Isolda Pereira da. REVISTA RENE FORTALEZA. Parto normal ou cesárea? Uma avaliação a partir da percepção das parturientes. Fortaleza: 2001, jul./dez. v. 2, n. 2, p. 87-93.

Obstetrícia. In: GUIMARÃES, Deocleciano Torrieri: organização.

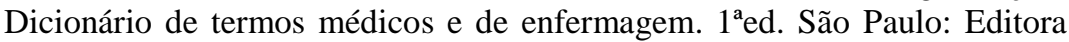
Rideel, 2002. p. 330.

OLIVEIRA, Sonia Maria Junqueira Vasconcellos de; RIESCO, Maria Luiza Gonzalez; MIYA, Claudia Fumiko Rosas; VIDOTTO, Paula. REVISTA LATINO AMERICANA ENFERMAGEM. Tipo de parto: expectativas das mulheres. São Paulo: 2002 set-out; 10(5):667-674.

ORGANIZAÇÃO MUNDIAL DE SAÚDE. Declaração da OMS sobre taxas de cesáreas. Word Health Organization. Institutional repository for information sharing.p. 1-8.2015.Disponível em:

<http://apps.who.int/iris/bitstream/10665/161442/3/WHO_RHR_15.02_por. pdf?locale=es\&null $>$ Acessado em: 28 abril 2016.

PARANÁ. Secretaria de Estado da Saúde. Natural é o parto normal: prénatal, parto e puerpério.3.ed. Curitiba - Pr, 2004.

PIMENTA, Lizandra Flores; RESSEL Lúcia Beatriz; SANTOS Carolina Carbonell dos; WILHELM, Laís Antunes .The perceptions of woman about the choice of delivery modes: a descriptive study. Online Braz j nurs. 2013 Apr (cited year month Day); 12 (1): 135-144. ISSN: 1676-4285. Disponível em: 〈http://www.objnursing.uff.br/index.php/nursing/article/view/3963> Acessado em: 06 abril 2016

QUEIROZ, Marcel Robledo.Curso de obstetrícia da escola de artes, ciências e humanidades da universidade de São Paulo - USP. O que é obstetrícia?. 2013. p. 1-2. <http://www.each.usp.br/obstetricia/obstetricia.htm> Acesso em: 05 de junho 2016

REVISTA ENFERMAGEM. Publicação oficial do conselho de enfermagem de São Paulo.COREN-SP. Parto natural e parto normal: quais as diferenças?. Ano 10, $\mathrm{n}^{\circ} 81$, jul/2009. p.21-25. 


\section{BIBLIOGRAFIA COMPLEMENTAR}

CABRAL, Antônio Carlos Vieira; AGUIAR, Regina Amélia L.P.de; VITRAL, Zilma Nogueira Reis. Manual de assistência ao parto. São Paulo: Atheneu, 2002. p.01

COSTA, Solange Fátima Geraldo da; CARNEIRO, Alan Dionizio; MORAIS, Gilvânia Smith da; SOUZA, Mariana Campos de. Assistência à mulher no ciclo gravídico-puerperal: aspectos éticos e legais do enfermeiro. Disponível em:

$<$ http://apps.cofen.gov.br/cbcenf/sistemainscricoes/arquivosTrabalhos/assist encia\%20a\%20mulher.pdf>

Acesso em: 14 abr.2016.

STRIGHT, Barbara R; HARRISON, Lee Olive. Enfermagem materna e neonatal. 2.ed. Rio de Janeiro: Guanabara Koogan, 1998. p. 1-2. 
